\title{
Assay of Hydroxypropoxy Group in Hydroxypropyl Cellulose by United States Pharmacopeia-Titration Method
}

\author{
Y. Yildiz ${ }^{1, *}$, M. Dasguptha ${ }^{2}$ \\ ${ }^{1}$ Complete Analysis Laboratories, Analytical Chemistry Research Department, 810 North 2nd Ave, Highland Park, NJ. 08904-USA \\ ${ }^{2}$ Eutech Scientific Services, Analytical Chemistry Research Department, 810 North $2^{\text {nd }}$ Ave, Highland Park, NJ. 08904-USA \\ *Corresponding author: sayatoglu@yahoo.com
}

\begin{abstract}
Hydroxypropyl cellulose (HPC) is a derivative of cellulose with both water soluble and organic solubility, used as food additive and sieving matrix for DNA separation. Hydroxypropyl Cellulose is partially substituted poly (hydroxypropyl) ether of cellulose. It contains NLT 53.4\% and NMT 80.5\% of hydroxypropoxy groups, calculated on the dried basis. It may contain ether suitable anticaking agents, and 0.6 percent of silica $\left(\mathrm{SiO}_{2}\right)$. The average sample result has been determined $67.3 \%$ which was conforms to USP/NF specifications for Hydroxypropyl cellulose.
\end{abstract}

Keywords: Hydroxypropoxy group, Hydroxypropyl Cellulose, assay test

Cite This Article: Y. Yildiz, and M. Dasguptha, “Assay of Hydroxypropoxy Group in Hydroxypropyl Cellulose by United States Pharmacopeia-Titration Method.” World Journal of Analytical Chemistry, vol. 6, no. 1 (2018): 1-3. doi: 10.12691/wjac-6-1-1.

\section{Introduction}

Hydroxypropyl cellulose (Cellulose, 2-hydroxypropyl ether) (HPC) is an ether of cellulose where some of the hydroxyl groups of the cellulose have been hydroxypropylated forming $-\mathrm{OCH}_{2} \mathrm{CH}(\mathrm{OH}) \mathrm{CH}_{3}$ groups using propylene oxide. Chemical formula of Hydroxypropyl ether of cellulose is $\left[\mathrm{C}_{6} \mathrm{H}_{7} \mathrm{O}_{2}(\mathrm{OH})_{\mathrm{x}}\left(\mathrm{OCH}_{2} \mathrm{CHOHCH}_{3}\right)_{\mathrm{y}}\left(\mathrm{OCH}_{2} \mathrm{CH}\left[\mathrm{R}_{\mathrm{w}}\right] \mathrm{CH}_{3}\right)_{2}\right]_{\mathrm{n}}$. $\mathrm{R}$ is a substituent comprising " $\mathrm{w}$ " hydroxypropoxyl group. Structural formula is shown at Figure 1. HPC is a nonionic water soluble cellulose ether with a remarkable combination of properties. It combines organic solvent solubility, and surface activity. HPC is a white or yellowish-white powder or granules, hygroscopic after drying soluble in cold water in glacial acetic acid, in anhydrous ethanol, in methanol and in propylene glycol and in a mixture of 10 parts of methanol and 90 parts of methylene chloride giving colloidal solutions, sparingly soluble or slightly soluble in acetone, practically insoluble in hot water, in ethylene glycol and in toluene. [1]

HPC is used as a lubricant for severe dry eye syndromes. $[2,3,4]$ HPC is also used as a thickener, a low level binder and as an emulsion stabilizer with $\mathrm{E}$ number $\mathrm{E}_{463}$. In pharmaceuticals it is used as a binder [5] in tablets. HPC is also used as a food additive, sieving matrix for DNA separations by capillary and microchip electrophoresis [6].

Hydroxypropyl cellulose is a physiologically inert substance, in a study of rats fed hydroxypropyl cellulose or unmodified cellulose at levels up to $5 \%$ of their diet; it was found that the two were biologically equivalent in that neither was metabolized. HPC is not absorbed from the gastrointestinal tract and is quantitatively excreted in the faces.

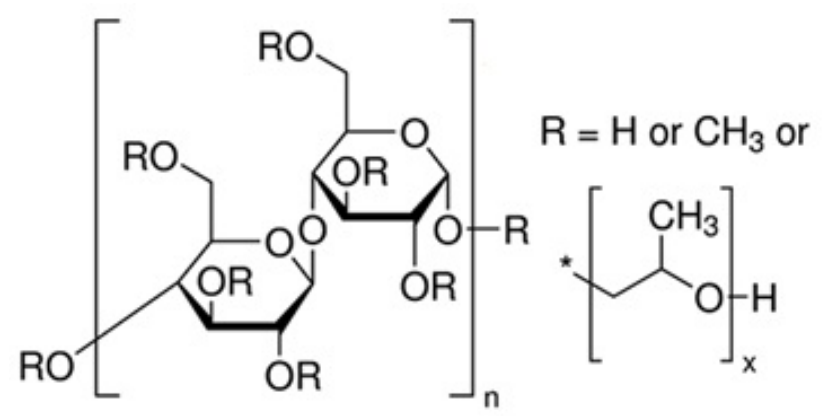

Figure 1. Structural formula of Hydroxypropyl Cellulose

\section{Materials and Method}

\subsection{Apparatus and Chemicals}

\subsubsection{Reagents}

- Sodium bicarbonate, $\mathrm{NaHCO}_{3}$

- Potassium iodide. KI

- Hydroxypropylcellulose raw materials were supplied by DOW USA Chemical Corporation, F4M premium grade

\subsubsection{Solutions}

- D. I Water

- Chromium Trioxide Solution

- $0.02 \mathrm{~N}$ Sodium Hydroxide Volumetric Solution 
- Sodium bicarbonate

- 2N Sulfuric acid Test Solution

- Potassium Iodide

- $0.02 \mathrm{~N}$ Sodium Thiosulfate Volumetric Solution

- Starch Indicator test solution.

- USP Hydroxypropyl Cellulose RS

\subsection{Equipment}

- Analytical balance

- Thermometer

- Timer

- Hydroxypropoxy determination apparatus (reaction flask).

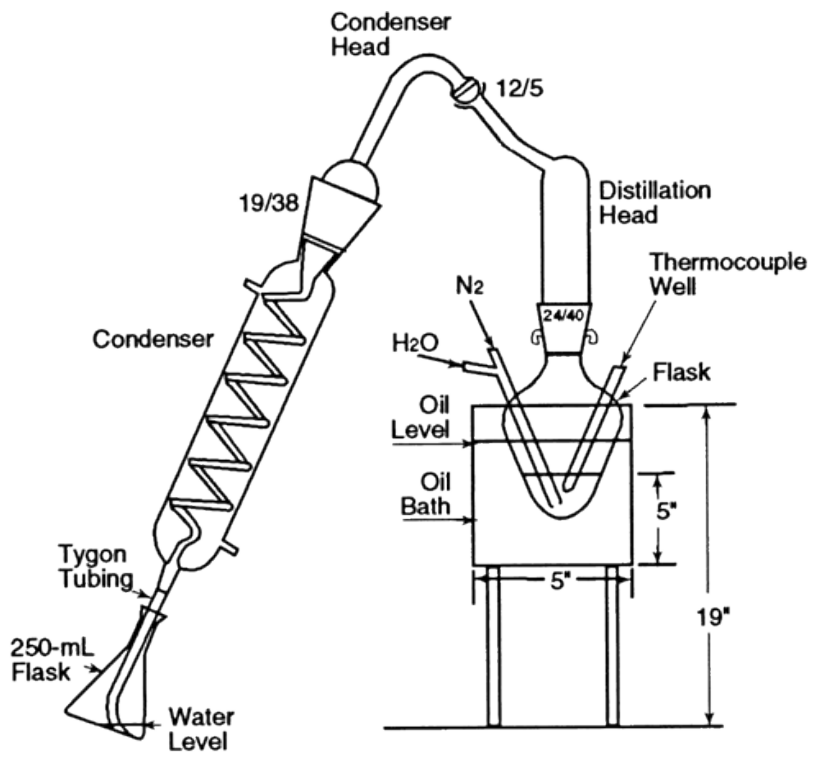

Figure 2. Reaction flask for hydroxypropoxy determination [1]

The boiling or reaction flask, consisting of a 125-mL conical-bottom boiling flask modified to provide a thermocouple (or thermometer) well and an inlet with a 1.0-mm capillary tip for nitrogen and water is fitted with a distillation head that leads to a condenser. The reaction flask is immersed in an oil bath equipped with an electric heater capable of heating the bath at the desired rate and maintaining the temperature at $155^{\circ}$. The distillate is collected in a flask. [NOTE-the tube from the condenser to the flask must be below the surface of the liquid in the flask to ensure the capture of all of the acetic acid formed [Figure 2] [1].

\section{Procedure Analysis}

Transfer about $65 \mathrm{mg}$ of Hydroxypropyl Cellulose, previously dried at $105^{\circ}$ for 1 hour and accurately weighed, into the reaction flask. Add $5 \mathrm{~mL}$ of water, and swirl gently for 5 minutes. Add $10 \mathrm{~mL}$ of chromium trioxide solution (30 g in $70 \mathrm{~mL}$ ). Assemble the apparatus as shown in Figure 2 and immerse the reaction flask in the oil bath slightly above the level of the chromium trioxide solution. Start the condenser cooling water, and pass nitrogen gas through the flask at a rate of about 70 to 75
$\mathrm{mL}$ per minute. Raise the temperature of the oil bath to $155^{\circ}$ during a 30-minute period, and maintain it at this temperature throughout the determination. [NOTE- too rapid an initial rise in temperature results in high blank determinations. Monitor the temperature of the reaction mixture in the reaction flask using a thermocouple or thermometer in a well, as shown in Figure 2. When a reaction mixture temperature of $102 \pm 1^{\circ}$ is reached, add water through the water inlet until the reaction mixture temperature drops to $97 \pm 1^{\circ}$. Continue this $97^{\circ}$ to $102^{\circ}$ temperature cycle until $100 \mathrm{~mL}$ of distillate has been collected. Detach the condenser from the distillation head, and wash with water, collecting the washings in the flask containing the distillate. Titrate the solution with $0.02 \mathrm{~N}$ sodium hydroxide VS to a $\mathrm{pH}$ of $7.0 \pm 0.1$, using an expanded-scale $\mathrm{pH}$ meter equipped with glass and calomel electrodes. Record the volume, $V$, of the $0.02 \mathrm{~N}$ sodium hydroxide used, then add $500 \mathrm{mg}$ of sodium bicarbonate and $10 \mathrm{~mL}$ of $2 \mathrm{~N}$ sulfuric acid. After evolution of carbon dioxide has ceased, add $1 \mathrm{~g}$ of potassium iodide, insert the stopper in the flask, shake the mixture, and allow the solution to stand in the dark for 5 minutes. Titrate the liberated iodine with $0.02 \mathrm{~N}$ sodium thiosulfate VS to the sharp disappearance of the yellow iodine color, adding a few drops of starch TS to confirm the endpoint. Record the volume, $Y$, required. This titration, $Y \mathrm{~mL}$, multiplied by the empirical factor, $K$, appropriate to the particular apparatus and reagents in use (see calculation below), gives the acid equivalent not caused by acetic acid. The acetic acid equivalent is $(V=K Y) \mathrm{mL}$ of $0.02 \mathrm{~N}$ sodium hydroxide.

Obtain the empirical factor, $K$, for the apparatus by performing a blank determination in which the Hydroxypropyl Cellulose is omitted. The acidity of the blank for a given apparatus and given reagents is in a fixed ratio to the oxidizing equivalent of the distillate in terms of sodium thiosulfate:

$$
K \text { factor }=\left(V_{B} \times N_{1}\right) /\left(Y_{B} \times N_{2}\right)
$$

in which $V_{B}$ is the volume, in $\mathrm{mL}$, of $0.02 \mathrm{~N}$ sodium hydroxide required in blank run; $N_{1}$ is the normality of the $0.02 \mathrm{~N}$ sodium hydroxide; $Y_{B}$ is the volume, in $\mathrm{mL}$, of $0.02 \mathrm{~N}$ sodium thiosulfate required in blank run; and $N_{2}$ is equal to the normality of the $0.02 \mathrm{~N}$ sodium thiosulfate.

Calculate the percentage of hydroxypropoxy groups $\left(-\mathrm{OCH}_{2} \mathrm{CHOHCH}_{3}\right)$ by the formula:

$$
100\left(V_{A} N_{1}-K Y_{A} N_{2}\right)(0.079 / W)
$$

in which $V_{A}$ is the volume, in $\mathrm{mL}$, of $0.02 \mathrm{~N}$ sodium hydroxide required for titration of the sample; $N_{1}$ is the normality of the $0.02 \mathrm{~N}$ sodium hydroxide; $K$ is the empirical factor; $Y_{A}$ is the volume, in $\mathrm{mL}$, of $0.02 \mathrm{~N}$ sodium thiosulfate required for titration of the sample; $N_{2}$ is the normality of the $0.02 \mathrm{~N}$ sodium thiosulfate; and $W$ is the quantity, in $\mathrm{g}$, of sample used. Each $\mathrm{mL}$ of $0.02 \mathrm{~N}$ sodium hydroxide is equivalent to $1.502 \mathrm{mg}$ of hydroxypropoxy groups $\left(-\mathrm{OCH}_{2} \mathrm{CHOHCH}_{3}\right)$ [7].

The results obtained as a percentage of hydroxypropoxy content may be converted to terms of average molecular substitution of glucose units by means of the accompanying graph (Figure 3) 


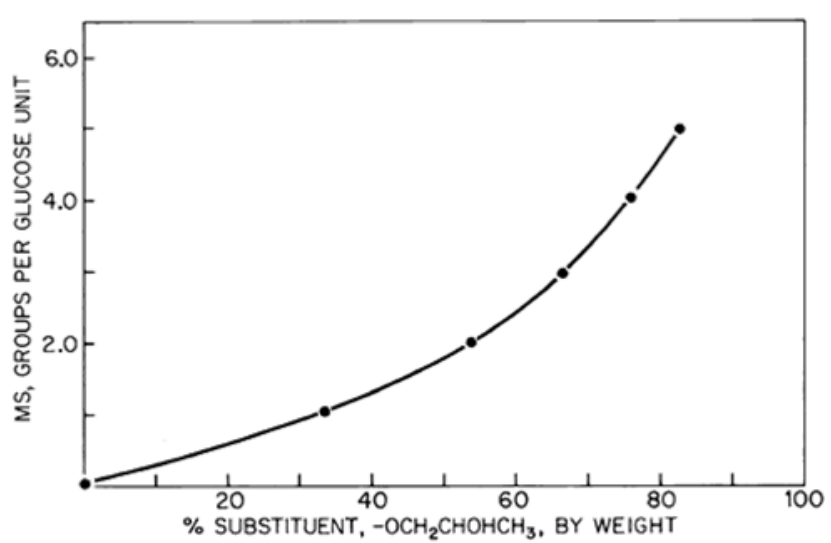

Figure 3. Graph for converting percentage of substitution, by weight, of hydroxypropoxy groups to molecular substitution per glucose unit [1]

\section{Result and Discussion}

\subsection{Calculations for Hydroxypropylcellulose}

$65.0 \mathrm{mg}$ of hydroxypropylcellulose was swirled in 5 $\mathrm{mL}$ water for $5 \mathrm{~min}$. To this was added $10 \mathrm{~mL}$ of $30 \mathrm{~g} / 70$ $\mathrm{mL} \mathrm{Cr}_{2} \mathrm{O}_{3}$ solution to optimize dissolution of sample. Take $1 / 2 \mathrm{hr}$ to reach operating temperature, with argon flowing, on oil bath, as per official monograph.

Titrated with $0.01947 \mathrm{~N} \mathrm{NaOH}$ (as standardized with $\mathrm{HCl}$ ) to $\mathrm{pH}$ 7.00. Sample was required $28.90 \mathrm{~mL}$ of $\mathrm{NaOH}$. A blank was required $0.20 \mathrm{~mL}$ of $\mathrm{NaOH}$. Then add $0.5 \mathrm{~g}$ $\mathrm{NaHCO}_{3}$ and $10 \mathrm{~mL}$ of $2 \mathrm{~N} \mathrm{H}_{2} \mathrm{SO}_{4}$; after production of
$\mathrm{CO}_{2}$ (g) ceases, add $1 \mathrm{~g} \mathrm{KI}$, stopper and shake, kept in dark for $5 \mathrm{~min}$, and titrated with $0.020 \mathrm{M}$ thiosulfate. Sample was required $0.80 \mathrm{~mL}$ thiosulfate; blank was required $0.02 \mathrm{~mL}$ thiosulfate (Table 1 ).

$$
\mathbf{K}=\frac{(V B \times N 1)}{(Y B \times N 1)}=\frac{0.20 \times 0.01947}{0.30 \times 0.02030}=0.6394
$$

\% Hydroxypropoxy groups

$$
=\left(\mathrm{V}_{\mathrm{A}} \mathrm{N}_{1}-\mathrm{KY}_{\mathrm{A}} \mathrm{N}_{2}\right) \times\left(\frac{0.079}{W}\right) \times 100
$$

Test A

$$
\begin{aligned}
& \text { \% Hydroxypropoxy groups } \\
& =(28.90 \times 0.01974-0.6394 \times 0.80 \times 0.02030) \\
& \quad \text { x }\left(\frac{0.079}{0.0658}\right) \times 100 \\
& =67.25 \%
\end{aligned}
$$

Test B (duplicate)

$$
\begin{aligned}
& \text { \% Hydroxypropoxy groups } \\
& =(28.88 \times 0.01974-0.6394 \times 0.78 \times 0.02030) \\
& \times\left(\frac{0.079}{0.0656}\right) \times 100 \\
& =67.44 \%
\end{aligned}
$$

Average of percent Hydroxypropoxy groups: 67.3\%, and meets the United States Pharmacopeia (USP/NF) specification for Hydroxypropyl cellulose.

Table 1. Results for Assay

\begin{tabular}{|c|c|c|c|c|c|c|c|}
\hline Identity & $\begin{array}{c}\text { Volume } V_{A} \text { of } \\
\text { the } 0.02 \mathrm{~N} \\
\mathrm{NaOH}(\mathrm{mL})\end{array}$ & $\begin{array}{c}\text { Volume } \mathrm{Y}_{\mathrm{A}}, Y_{B} \\
\text { of the } 0.02 \mathrm{~N} \\
\mathrm{Na}_{2} \mathrm{~S}_{2} \mathrm{O}_{3}(\mathrm{~mL})\end{array}$ & $\begin{array}{c}\text { Empirical factor, } \mathbf{K} \\
\frac{(V B x N 1)}{(Y B x N 2)}\end{array}$ & $\begin{array}{c}\text { Sample } \\
\text { weight (mg) }\end{array}$ & $\begin{array}{c}\text { Normality } \\
\text { of NaOH }\end{array}$ & $\begin{array}{c}\text { Normality } \\
\text { of } \mathrm{S}_{2} \mathrm{O}_{3}\end{array}$ & $\begin{array}{c}\text { Hydroxypropoxy } \\
\text { Groups (\%) }\end{array}$ \\
\hline Blank & 0.20 & 0.02 & 0.6394 & ----- & 0.01947 & 0.02030 & ---- \\
\hline Test A & 28.90 & 0.80 & ---- & 0.0658 & 0.01947 & 0.02030 & 67.25 \\
\hline Test B & 28.88 & 0.78 & ----- & 0.0656 & 0.01947 & 0.02030 & 67.44 \\
\hline
\end{tabular}

\section{References}

[1] British Pharmacopoeia 2003. Hydroxypropyl Cellulose Monograph.

[2] Luchs J, Nelinson D, Macy J (December 2010). "Efficacy of hydroxypropyl cellulose inserts (LACRISERT ${ }^{\circledR}$ ) in subsets of patients with dry eye syndrome (DES): Findings from a patient registry". Cornea. 29 (12): 1417-1427.

[3] McDonald M; D’Aversa G; Perry D; Wittpenn J; Nelinson D (Oct 2010). "Correlating patient- reported response to Hydroxypropyl cellulose ophthalmic insert (LACRISERT®) therapy with clinical outcomes: tools for predicting response". Curr Eye Res. 35 (10): 880-887.
[4] Koffler B, McDonald M, Nelinson D (May 2010). "Improvement in clinical signs, symptoms, and QoL associated with DES: Hydroxypropyl Cellulose Ophthalmic Insert PatientRegistry". Eye and Contact Lens. 36 (3): 170-176.

[5] Weiner, Myra L.; Lois A. Kotkoskie (1999). Excipient Toxicity and Safety. p. 8.

[6] Sanders, J. C.; Breadmore, M. C.; Kwok, Y. C.; Horsman, K. M.; Landers, J. P., Hydroxypropyl cellulose as an adsorptive coating sieving matrix for DNA separations: artificial neural network optimization for microchip analysis. Anal Chem 2003, 75, (4), 986- 94". Cat.inist.fr. Retrieved 2011-11-10.

[7] USP 40/ NF 35 United States Pharmacopeia Official Monographs: Hydroxypropyl Cellulose. 